\title{
What is a brain, and who said so?
}

\author{
MARTIN G NETSKY
}

A love affair with dictionaries began when I was a schoolboy. My parents encouraged me to "look it up in the dictionary" whenever a word was questioned. It was an ingenuous time. The meaning of a word was enshrined in the dictionary, and words existed because they were recorded there. When someone said "ain't" we chanted, "Ain't ain't a word, because ain't ain't in the dictionary." The concept that lexicographers might be incorrect, uninformed, lazy, or plagiaristic did not enter my credulous mind.

I collect dictionaries and might be called a lexicophile. The Oxford University Press depends on my trade: I own the 12 volume set, the supplements, the shorter, the concise, the pocket, and the little editions. Not only do I have monolingual, bilingual, and multilingual dictionaries, including one in Siamese, but lexicons of wines, cheeses, printing, wit and wisdom, word origins, psychology, slang, difficult words, international slurs, criminology, etymology, similes, metaphors, and obsolete English. The Devil's Dictionary by Ambrose Bierce is the most inventive and the wittiest. Few other lexicographers are esteemed for originality or for a sense of humour.

\section{What is a brain?}

The question of defining the word brain arose when a colleague and I submitted for publication a paper on the evolution of the human brain. We thought it might be amusing to consider whether the dinosaurial, lumbosacral enlargement was an underslung brain or if a non-cranial ganglion could appropriately be called a brain. Many recent medical dictionaries still describe the coeliac plexus as the abdominal brain or cerebrum abdominale. The concept of a brain in the abdomen or pelvis is a difficult one for me.

In our paper we considered criteria to distinguish a brain from a ganglion. We knew that the brain may be viewed as a cranial ganglion but had the anthropocentric arrogance to contend that, although the human encephalon is part of the scheme of evolution, it is also unique. Brains of other species have not conceived sonatas or nuclear weapons. Our manuscript concerned the planarian (flatworm) brain as the probable ancestor of the human brain. The editor sent the paper to several invertebratologists, who took umbrage at raising the Pyrrhonism of whether some lower forms had a brain. These scientists are known also as invertebrate zoologists but they are not spineless. They authoritatively stated that their work nullified our concept and advised abandoning that discussion. We complied for the sake of publication and our well deserved reputation as good fellows. I then decided to analyse definitions of brain in various dictionaries. The multiple inadequacies will be considered, and an improved definition proposed.

\section{Defining definitions}

Firstly, what is the definition of a definition? Philosophers since Plato have told us, but not too clearly. Robinson (1954) considered this question and other issues, such as "Should a definition be brief?" (answer: there are views on both sides); "Are there indefinables? (answer: see first question); "Have definitions a truth

\footnotetext{
Department of Pathology, Vanderbilt University School of Medicine, Nashville, Tennessee 37232

MARTIN G NETSKY, MD, emeritus professor of pathology
}

value?" (the usual response); and, "Is definition a useful procedure or not?" (by now the reader knows the answer).

The puissant Oxford English Dictionary (1933) defined definition as:

1 The setting of bounds or limits...

2 The action of determining a controversy or question at issue...

3 The action of defining, or stating exactly what a thing is, or what a word means

4 A precise statement of the essential nature of a thing: a statement or form of words by which anything is defined

5 The act of making definite...

Meanings 3 and 4 are nearest to our concerns. Portions of these statements are circular - that is, they use the word define. Some authorities argue it cannot be otherwise; the meaning of a word is a set of words for the same thing. I will use "A precise statement of the essential nature of a thing" and will judge what is precise and essential. These two words, however, will not be defined in the interests of brevity.

The Oxford English Dictionary gave four definitions of brain:

1 The convoluted mass of nervous substance contained in the skull of man and other vertebrates... is also applied by extension to the analogous but less developed organs of invertebrate animals

2 Marrow; the pith or heart of the growth at the top of the date-palm. Obs.

3 Considered as the centre of sensation, the organ of thought, memory, or imagination...

4 Intellectual power, intellect, sense, thought, imagination (from 16th c on, often plural)

The first definition is strictly anatomical. The brain, however, is a working organ; surely the definition should include function, unless we are defining a dead brain. The second definition is obsolete and not relevant to this study except to illustrate the peculiarities of our language. The "brain of the date-palm" sounds odd, perhaps indicating my ignorance of palm trees, except for the delicious heart of palm. Some activities of the brain are given separately in meanings 3 and 4 . Neither speech nor control of motion is cited.

\section{The function of a brain}

Is "convoluted" essential? This word is not used in any other dictionary. The brain of the fetus is not convoluted, neither is that of small animals such as the mouse. Convoluted is therefore neither precise nor essential in the definition of a vertebrate brain. The Oxford English Dictionary also notes that early scientific writers restricted use of "brain" to the anterior part, the cerebrum, in contrast to the posterior part, the cerebellum. Today we distinguish cerebrum from cerebellum, but brain universally means the entire organ including the brain stem.

Let us peregrinate through the years to observe how the brain has been defined. We begin in 1755 when Samuel Johnson published the greatest of all dictionaries. Brain was:

That collection of vessels and orgars in the head from which sense and motion arise.

The brain is divided into cerebrum and cerebellum. Cerebrum is that part of the brain which possesses the upper and forepart of the brain, being separated from the cerebellum by the second process of the dura mater, under which the cerebellum is situated. The substance of the brain is distinguished into inner and outer; the former is called corticalis, cinerea, or glanduosa; the latter meduliaris, alba, or nervea. [Cheselden]

Johnson's definition is indeed remarkable. He recognised the living brain as a functioning organ. What the brain does is as fundamental to the definition as where it is located or the names of its parts. He carefully selected neuroanatomic details 
from Cheselden's The Anatomy of the Human Body (1712). The acknowledgement is unusual. Lexicographers seldom credit the primary definition to those people being quoted. Johnson recognised the brain as the seat of motion as did few others. Citing inner and outer substance, white and gray matter, is also rare in a lexicon. Most authors have not thought the statement necessary; but a cortex of neurons is an important feature of the vertebrate brain. Johnson's statement uniquely includes "vessels." Are blood vessels necessary in the definition? Probably not: organs require a supply of blood, but none is defined by its arteries and veins. The only other word that arouses a quibble today is "glandulosa."

\section{American versions}

Noah Webster was the first great American lexicographer. He was motivated by patriotism and by antagonism to British dictionarians. His definitions were mostly one liners. In 1806 he defined brain as "A soft substance within the skull; the seat of sensation and intellect." The pioneers, Johnson and Webster, thought physiologically as well as anatomically. Webster was alone in deciding that consistency (softness) was essential. The statement is correct but is not needed to understand the structure and function of a brain. This organ is also fatty, highly aqueous, enclosed by membranes of connective tissue, and has central fluid filled cavities, but none of these features is essential in defining the word.

Robley Dunglison, a transplanted British professor of medicine at the University of Virginia, wrote a medical dictionary published in many editions from 1833-1903. His son became editor in 1874 . The headword brain was absent in the earliest versions. Cerebrum, however, was defined as the "brain" followed by a detailed anatomical description. Its function was "The material organ of thought - of the mental and moral manifestations." The anatomical discussion contained many non-essential features, but why was it buried as "cerebrum" rather than entered under "brain?"

The term brain appeared in the 10th edition (1853), tersely defined as "cerebrum." This word is a synonym but is incorrect because it excludes the cerebellum and brain stem. The definition of "cerebrum" was almost unchanged from 1833-95, when Dunglison's son finally used a proper synonym, "encephalon"; subheadings then listed parts of the brain, such as " $B .$, fore, prosencephalon; $B .$, mid, mesencephalon." Lexicographic inertia prevented the rewriting of the primary definition to include the subdivisions. In any event, brain was defined as a name or as the sum of various parts. "Encephalon" was merely "that which is situate in the head."

Why did Dunglison omit "brain" for so many years? My suggestion is that he considered it an ordinary word, not sufficiently grandiloquent for learned physicians. Once the decision was made correcting it was difficult. Johnson and Webster, lexicographers for the laity rather than for technicians, defined brain, but both authors excluded cerebrum and encephalon.

\section{Missing mesencephalon}

Gould's dictionary of 1903 said the brain was "that part of the central nervous system contained in the cranial cavity, and consisting of the cerebrum, the cerebellum, the pons, and the medulla oblongata." Most anatomists agree that the midbrain (mesencephalon) is neither the cerebrum nor the other structures cited. That fact was known to the younger Dunglison. Various editions of Gould appeared until 1941. Two versions of a New Gould Medical Dictionary were dated 1949 and 1956. There was nothing new, however, about the entry for "brain." Every word was the same. Were the lexicographers lazy or uninformed?

We may condone repetition within various editions of the same dictionary, but what of a dictionary written by another author? Dorland (1917) defined brain as: "The mass of nervous material contained within the cranium, including the cerebrum, cerebellum, pons, and medulla oblongata." The named parts of the brain were repeated as in Gould (1903) and are incomplete. The copying of errors can be designated as plagiarism - that is, borrowing without permission or acknowledgement. "Nervous material" or nervous substance" (Oxford English Dictionary) has two meanings. Nervous is defined as "having to do with nerves," but also as "readily upset." "Nervous material" may then be interpreted as "jumpy." Changing the order of words may result in different interpretations. A pathological professor is not the same as a professor of pathology, except in rare instances. "Nervous system," however, is fixed by usage. Another defect of "nervous material in the cranium" is that the phrase erroneously includes peripheral parts of the cranial nerves within the skull.

By 1981 the editors of Dorland's Medical Dictionary had improved their knowledge of neuroanatomy. Brain now was: "That part of the central nervous system contained within the cranium, comprising the prosencephalon, mesencephalon, and rhombencephalon; it is derived (developed) from the anterior part of the embryonic neural tube ...." For the first time an embryologic statement was used to define a brain. Should a definition be encyclopedic? What truths can be omitted while retaining precision and essentiality? The unequivocal answer is unknown. An overly full definition would include a statement of how the brain evolved, but readers should note my special interest in Evolution of the Nervous System (1981).

Stedman's Medical Dictionary was supposedly created independently. The 13th edition (1936) defined brain as "cerebrum, encephalon, the mass of nervous matter within the cranium." This entry was followed by subheadings that included "fore- $b$, prosencephalon," and so on. Stedman borrowed this material from the later Dunglison. The format is readily explained: Thomas L Stedman edited the last edition (1903) of Dunglison's dictionary and then published a lexicon under his own name in 1911. The 22nd edition in 1972 was "completely revised by a staff of 33 editors," but the entry under brain was the same as in 1936. The 24th edition (1982) slightly improved the definition to "That part of the nervous system contained within the cranium." Abdominal brain still was entered, but three new subheadings gave evidence of finally moving into the twentieth century: respirator brain, split brain, and visceral brain.

\section{Conflict of anatomy and function}

An absurd example of the inertia of lexicographers and the nonsense of antiquated medicine occurs in recent editions of both Dorland and Stedman, where cerebrum exsiccatum was still entered. For readers not familiar with this hoary therapeutic agent, it is (Dorland, 1981) "The gray substance of the brain of calves, freed from fats, dried and pulverized; used therapeutically in brain and nervous disease." Stedman (1982) stated this humbuggery was for the treatment of "cerebral neurasthenia."

Most lexicographers use only anatomical terms in defining the brain. The trailblazers, Johnson and Webster, include functions: sense and motion, and sensation and intellect, respectively. The Oxford English Dictionary in secondary definitions adds thought, memory, imagination, intellect, and sense. A human capacity of extraordinary importance-namely speech-is not mentioned in any dictionary. This absence cannot be explained by a reluctance to consider the human brain: intellect (as distinguished from intelligence) and imagination are not ascribed to other species. Furthermore, if the writers are describing vertebrate brains most omit four essential features: the brain has symmetrical hemispheres lying close together on either side of the midline; it has commissures between the hemispheres; it is continuous with the spinal cord; and it contains neuronal clusters such as the hypothalamus.

The function of organs, other than the brain, is freely given in most dictionaries. The Oxford English Dictionary, for example, admits that kidneys excrete urine, the liver secretes bile, and the heart supports the circulation of the blood. The complexity of cerebral function does not explain why lexicographers avoid the subject. "From which sense and motion arise" (Johnson) was not a complete statement of what the brain does, but a living organ was defined rather than an anatomic specimen.

New editions and supplements allow for errors to be corrected, 
new concepts added, and ancient material removed. Few editors revise the text for words such as brain, even when the definition is erroneous. They are too busy inserting the latest words and are inefficient in removing the barnacles. The supplements of the Oxford English Dictionary do not correct errors in the definition of brain, but add compound words such as brainstorm, and electronic brain (an unsuccessful description of the computer). The definition of brain in Dorland was incorrect and unchanged from 1917 to 1981. The improved version still defined a dead brain.

\section{Johnsonian excellence}

I conclude that if we seek a definition of brain medical dictionaries are an inferior source; the latest is not the best. Samuel Johnson in 1755 set a standard of excellence. What then may be said of the high art of making a dictionary more than 200 years later? Do vertebrate lexicographers have brains? Is the computer a brain destined to save medical lexicography? If not, where do we obtain help?

\section{Can a brain be defined?}

Finally, what is a brain? Can we synthesise the various definitions? Consider the leading nouns: mass, collection, substance, part, material, cerebrum, and encephalon. These nouns are so disparate that we are amazed that the same word is being defined. We can argue, however, that a general word is needed, and then is particularised, but the details also are diverse. Some lexicographers, for example, say that the substance of the brain is jumpy. Uniformity is noted only with regard to location of the brain: skull, head, cranium, or cranial cavity. Use of dictionaries allows us to be certain only that the brain is something in the appendage rostral to the neck.

I offer, for target practice, the following definition of a vertebrate brain: that part of the central nervous system in the skull; connected to the spinal cord; the seat of sense, motion, thought, and of human speech; comprising two contiguous hemispheres connected by commissures; a cortex of neurons, the gray matter, surrounds both white matter and various subcortical neuronal clusters.

\section{Three into five won't go}

\section{T B ANDERSON}

Doctors who practise in professional isolation do so mostly from deliberate choice. Dr Edward Wilson in Antarctica or Dr Albert Schweitzer in central Africa accepted a hostile environment as part of their terms of service. For me it was different. I joined the Royal Fleet Auxiliaries (RFA) after 35 years in general medical practice, hoping to see the world. My most exotic tour to date had been with the Royal Army Medical Corps in Palestine during the troubles after the second world war. And I had brief acquaintance with the RFA in 1965 with the Royal Research Ship Discovery on an oceanographic survey of the mid-Atlantic. Both experiences gave me a taste of clinical independence. In $1945 \mathrm{I}$ was isolated by snow in the Lebanese Alps with another RAMC subaltern. We had two emergencies - an acute appendicitis in an infantry colonel and a Turkish civilian with a fractured femur. We had inadequate equipment to deal with either. By the time that medical supplies had been dropped by air the colonel had responded to conservative treatment, Fowler's regimen, and sulphonamides. His appendix was removed at home and it was said, so he told me 30 years later, to show evidence of recent inflammation. We did our best for the Turk: with a Thomas' splint and a bucket of water to produce the tractive force. Our success was measured; after four days on traction the bad leg was half an inch longer than the good one. But our success was not rewarded; in the French hospital in Beirut the surgeon saw economic expediency in terms of amputation.

The Discovery was 400 miles due west of Lisbon when a young seaman reported his abdominal pain. He had appendicitis. I had no medical help, but the ship had a good, well equipped hospital. In the eyes of the ship's company there was no reason why their surgeon should not do the necessary operation. They did not know that I had never taken out an appendix without being supervised. I opted for Fowler's regimen again, adding chloramphenicol for good measure, and the patient underwent interval appendicectomy in the Royal Naval Hospital, Stonehouse.

\section{Cambridge CB3 9ED}

T B ANDERSON, MD, FRCGP

Correspondence to: 14 Grantchester Road, Cambridge CB3 9ED.
On 30 December 1981 I joined RFA Olna in Portland. I was excited, because going afloat is always exciting, but apprehensive at the prospect of having to face unforeseen clinical problems. But my first trip, to the Persian Gulf, gave me no more than a glimpse of the other side of the Middle East of which I had learnt a little when in the Army; Oman seemed like a very sunburnt Aldershot. On our way home we called at Haifa, where I had been stationed for a year in Peninsula Barracks, destined we believed in 1947 for demolition. They still stood in 1982 and were occupied by the Israeli navy. A peep through the perimeter wire recalled dormant memories.

\section{At war with Argentina}

I was quite settled into the seagoing life by the time we got home to Gosport, but the suspicion that we were to be involved in the war with Argentina became a certainty. I was unsettled again and began to feel the butterflies in the stomach; I knew nothing of naval warfare. The Royal Naval Hospital, Haslar, proved a rich source of help and reassurance of every kind; the anaesthetic department in particular allowed me to stand in on inductions and to practise intubation. Through the complexity of recent technical advances I discerned the truth; the techniques of yesteryear were still feasible so I could, if needed, use pentothal, gas, and oxygen with trilene or ether. The ship's Boyle's apparatus took on a friendly importance, and ceased to be just a piece of furniture; I was quite put out when a few days before we were due to sail the hospital anaesthetic technician pronounced it unusable. A replacement arrived in the nick of time; shining and with a confidence of its own it seemed to anticipate my conjectures-those amputations, blast injuries, penetrating wounds of chest and abdomen, brain damage. ...

We sailed from Gosport on 10 May. HMS Sheffield had already been lost and we had on board a Royal Naval lieutenant, trained in nuclear, biological, and chemical warfare, who gave lectures based on the analysis of the damage reported from the Sheffield. He instructed us on how best to reduce damage to our own ship. He emphasised the danger caused by the combustion of insulating plastics, releasing bromine and cyanides. He left the ship by helicopter as we passed Ascension Island. I mulled over the facts and lost my only crumb of comfort. I had with others believed that 